\title{
The assessment of decision-making competence in
}

\section{patients with depression using the MacArthur \\ Competence Assessment Tools: A systematic review}

- Running Head: MacArthur Competence Assessment Tool

Yuan-Yuan Wang, PhD, Postdoctoral Fellow ${ }^{1 \#}$

Shi-Bin Wang, PhD, Postdoctoral Fellow ${ }^{1 \#}$

Gabor S. Ungvari, MD, PhD, Professor ${ }^{2,3}$;

Xin Yu, MD, Professor ${ }^{4}$;

Chee H. Ng, MBBS, MD, Professor ${ }^{5}$;

Yu-Tao Xiang, MD, PhD, Associate Professor ${ }^{1 *}$

1. Unit of Psychiatry, Faculty of Health Sciences, University of Macau, Macao SAR, China;

2. University of Notre Dame Australia / Marian Centre, Perth, Australia;

3. School of Psychiatry \& Clinical Neurosciences, University of Western Australia, Perth, Australia;

4. Peking University Sixth Hospital, Peking University Institute of Mental Health, Key Laboratory of Mental Health, Ministry of Health (Peking University), Beijing, China;

5. Department of Psychiatry, University of Melbourne, Melbourne, Victoria, Australia

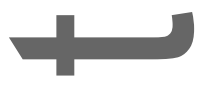

This is the anthon anuscript accepted for publication and has undergone full peer review but has not been through the pyediting, typesetting, pagination and proofreading process, which may lead to difference oet een this version and the Version of Record. Please cite this article as doi:

$10.1111 / \mathrm{ppou} 224$.

This article is protected by copyright. All rights reserved. 
\# These authors contributed equally to the work.

* Address correspondence to Dr. Yu-Tao Xiang, 3/F, Building E12, Faculty of Health Sciences, University of Macau, Avenida da Universidade, Taipa, Macau SAR, China. Fax: +853-2288-2314; Phone: +853-8822-4223;

E-mail: xyutly@gmail.com

\section{ACKNOWLEDGEMENTS}

The study was supported by the University of Macau (SRG2014-00019-FHS; MYRG2015-00230-FHS; MYRG2016-00005-FHS). The University of Macau had no role in the study design, generating or interpreting the results and publication of the study.

\section{DISCLOSURE STATEMENT}

There is no conflict of interest concerning the authors in conducting this study and preparing the manuscript.

\section{ABSTRACT}

PURPOSE: This is a systematic review of the usefulness of the MacArthur Competence Assessment Tools (MacCAT) in assessing the decision-making competence in patients with depression.

DESIGN AND METHODS: A systematic literature search was performed.

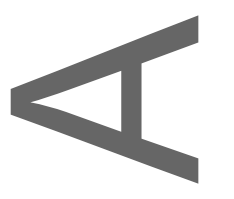


FINDINGS: Eleven studies met the search criteria. The decision-making capacity was impaired in $9 \%-31 \%$ of patients with depression. There was inconsistency regarding the differences of MacCAT scores between patients with depression and controls, while relatively large effect sizes were found on the Appreciation and Reasoning MacCAT subscales.

PRACTICE IMPLICATIONS: The MaCCAT appears to be a useful tool for measuring decision-making capacity in patients with depression, but the association between depression and competence is not consistent. The mechanisms mediating such association are likely to be complex and multifactorial.

Key words: Decision-making capacity, depression, MacArthur Competence Assessment Tools, systematic review

\section{INTRODUCTION}

The assessment of competence is important in judging patients' capacity to give consent to clinical care or participate in research. According to contemporary understanding on informed consent (Dunn et al., 2006; Lamont, Jeon, \& Chiarella, 2013; Sturman, 2005; Vellinga, Smit, van Leeuwen, van Tilburg, \& Jonker, 2004), patients should have adequate understanding of the choices and have the capacity to give consent which 
must be given entirely voluntarily. Several psychiatric disorders, such as depression, psychoses or dementia, could impair decision-making capacity (Hindmarch, Hotopf, \& Owen, 2013). Given the high prevalence of depression worldwide, it is important to examine its impact on decision-making capacity (Meynen, 2011),.

Over the past decades, several reliable and valid assessment tools for competence related to functional abilities have been developed including the various versions of the MacArthur Competence Assessment Tool (MacCAT) (Appelbaum \& Grisso, 1995; Appelbaum \& Roth, 1982; Grisso \& Appelbaurm, 1995; Grisso, Appelbaum, Mulvey, \& Fletcher, 1995). These versions include the MacArthur Competence Assessment Tool for Treatment (MacCAT-T), the MacArthur Competence Assessment Tool for Clinical Research (MacCAT-CR) and the MacArthur Competence Assessment Tool for Criminal Adjudication (MacCAT-CA) (Poythress, Bonnie, Monahan, Otto, \& Hoge, 2002). All these versions have been widely used in psychiatry. These are semi-structured interviews with four subscales assessing four components of decision-making capacity: Understanding, Appreciation, Reasoning, and Expression of a Choice. However, there is no consensus 
regarding the cut-off points of the MacCATs to categorise the levels of competence impairment.

The basic MacCAT measures decision-making capacity in psychiatric patients in the following aspects: Understanding Treatment Disclosure (UTD), Perception of Disorder (POD), and Thinking Rationally about Treatment (TRAT). The basic MacCAT takes around 60-90 minutes to administer, but it is not recommended for clinical use because it is time-consuming (Grisso \& Appelbaum, 1995). The newly developed versions are far shorter; for example, the MacCAT-T designed for clinical settings requires about 15-20 minutes to complete (Grisso, Appelbaum, \& Hill-Fotouhi, 1997). The MacCAT-CR, derived from the MacCAT-T, has 21 structured items and takes 20-25 minutes to measure the same domains as the MacCAT-T: Understanding (13 items), Appreciation (3 items), Reasoning (4 items), and Expression of a Choice (1 item) (Appelbaum \& Grisso, 2001; Grisso \& Appelbaum, 1998). The MacCAT-CA is a 22-item structured interview for the pretrial assessment of adjudicative competence, which assesses only Understanding, Reasoning and Appreciation (Poythress et al., 2002). The MacCATs have been shown to 
have acceptable psychometric properties for assessing competence (Grisso et al.,1995).

Studies examining the usefulness of MacCATs in assessing the decision-making capacity in patients with depression have yielded conflicting results. In earlier studies, patients with depression showed poorer decision-making capacity compared to healthy controls (Cohen, McGarvey, Pinkerton, \& Kryzhanivska, 2004; Grisso \& Appelbaum, 1995), but more recent studies did not confirm this finding (Appelbaum, Grisso, Frank, ODonnell, \& Kupfer, 1999; Christopher et al., 2011; Maxmin, Cooper, Potter, \& Livingston, 2009; Owen et al., 2009).

One-review examined decision-making capacity in depression (Hindmarch et al., 2013), however, several studies (Christopher et al., 2011; Fisher et al., 2012; Maxmin et al., 2009; Redding, 1997) using the MacCAT were not included in this review. In addition, the rates of impaired decision-making capacity in depression and the quantitative analyses, such as effect size of impaired decision-making capacity between patients with depression and controls, have not been adequately examined. 
This is hence a systematic review of the usefulness of the MacArthur Competence Assessment Tools (MacCAT) in assessing the decision-making competence in patients with depression in different settings.

\section{METHOD \\ Search strategies}

The following terms "MacCAT", "decision making", "capacity", "competence", "depression" and "depressive disorder" were searched independently by two reviewers (YYW and SBW) using both English (the Medline, EMBASE, PsycINFO, Cochrane Library) and Chinese databases (WANFANG, and Chinese National Knowledge Infrastructure) from January 1995 (when MacCAT was first published) to May 2016. The reference lists of the relevant papers were also searched and first/correspondence authors were contacted for missing information if necessary.

\section{Study selection}

All original quantitative studies that (1) used the MacCAT to assess the decision-making capacities in depression, and (2) provided MacCAT scores were included, Case studies or interviews were excluded. Two reviewers (SBW and YYW) checked the titles and abstracts of the initial search results 
independently. Any inconsistencies or disagreements during these procedures were checked and resolved by a third reviewer (YTX). Then the full texts of the studies that met the selection criteria were obtained for data extraction

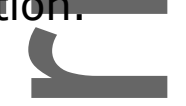

\section{Data extraction}

Data was independently extracted by two reviewers (YYW and SBW) and was checked by a third reviewer (YTX). The following information were extracted and tabulated: sample size, study setting and age of the participants, recruitment method, the MacCAT version, psychometric properties of the MacCAT, and correlations of depression with the scores of MacCAT subscales. Psychometric properties of the MacCAT included inter-rater agreement measured by the interclass correlation coefficient, kappa, test-retest correlation measured by the Kendall's tau, and inter-item or with the overall capacity judgment association. Where possible, effect sizes were computed in terms of Cohen's $d$ as benchmarks for assessing the magnitude of differences between patients and controls on MacCAT scores. RESULTS

There were 233 publications initially retrieved from the databases but only 15 publications met the selection criteria. Of the 15 studies, only data from 
11 studies were included because 4 publications used the same dataset (Figure 1). All 11 included studies were published in English-language journals. Table 1 displays the studies that met the selection criteria and provides an overview of their characteristics. Due to the heterogeneity of the selected studies in terms of study design, quality assessment measures were not used, and data analysis and synthesis could not be conducted.<smiles>[Os]</smiles>

Six studies used the MacCAT-T including the MacCAT original version, 4 studies applied the MacCAT-CR, and 1 study employed the MacCAT-CA. A total of 433 patients with depression (mean sample size per study was 39) were covered in the 11 studies.

Five-studies reported reliability figures of the MacCAT showing high levels of agreement with the kappa or interclass correlation coefficient being higher than 0.80 (Appelbaum et al., 1999; Appelbaum \& Redlich, 2006; Cairns et al.,2005; Maxmin et al., 2009; Vollmann, Bauer, Danker-Hopfe, \& Helmchen, 2003) although the component items and scoring rules varied between the MacCAT versions.

Rates of between 9\% (Maxmin et al., 2009) and 31\% (Owen et al., 2008) of patients with depression were classified as having impaired 
competence capacity based on different criteria. Using the MacCAT-T in three stuldies (Appelbaum \& Redlich, 2006; Lapid et al., 2003; Maxmin et al., 2009), the pooled scores of Understanding, Appreciation, Reasoning and Expression of a Choice in depression were estimated as 5.12 $(\mathrm{SE}=0.28), 3.87(\mathrm{SE}=0.07), 6.03(\mathrm{SE}=0.19)$ and $1.80(\mathrm{SE}=0.12)$, respectively (data are not shown in the Table). The pooled score using MacCAT-CR could not be calculated due to the inconsistency of scoring rules between studjes and missing data.

Comparisons between patients with depression and controls however showed inconsistency between studies: four studies found that depression impaired decision-making competency (Cohen et al., 2004; Grisso \& Appelbaum, 1995; Owen et al., 2009), but three studies could not replicate this finding (Appelbaum et al., 1999; Christopher et al., 2011; Maxmin et al., 2009). Relatively large effect sizes of the difference between patients and controls were found on the Appreciation (-0.69 in Cohen et al.'s study (Cohen et al., 2004)) and Reasoning component subscales (-0.85 in Cohen et al.'s study (Cohen et al., 2004) and -0.49 in the Grisso and Appelbaum's study (Grisso \& Appelbaum, 1998), but the effect size was small on the Understanding component subscale (-0.02 in Cohen et al.'s study (Cohen et 
al., 2004) and -0.04 in the Grisso and Appelbaum's study (Grisso \& Appelbaum, 1998). Furthermore, medium to large effect sizes were found on the Understanding, Appreciation and Reasoning subscales in comparisons between patients with depression, schizophrenia and dementia,(Table 1 ).

\section{DISCUSSION}

This review of 11 studies found considerable variability in study settings (inpatients or outpatients), sample sizes, age range of the participants, nature of interventions, and control groups ranging from non-psychiatric community volunteers to inpatients with neuropsychiatric diagnoses. Dementiarand schizophrenia patients were also included in some samples to explore the difference of their decisional capacity with patients with depression. Due to the sample heterogeneity, it was difficult to conduct complexanalyses and be conclusive on the general impact of depression on MacCAT score. However, a summary provided on the relationships between depression and MacCAT scores can assist further studies on the association between the severity of depression and MacCAT scores.

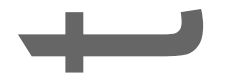

Apart from the depressive illness itself, decision-making capacity could be affected by other variables. The lack of capacity could be associated with 
increasing age, impaired insight and cognitive functions (Raymont et al., 2004). In younger adults, lack of decision-making capacity is usually associated with poor insight and psychosis, rather than cognitive impairment. However, in older psychiatric inpatients, intact capacity was related to higher levels of insight and cognition (Maxmin et al., 2009). There is a strong negative relationship between depressive mood and decision-making capacity, and a weak negative relationship between poor insight and decision-making competence in non-psychotic disorders (Owen et al., 2009).

In general, depression appears to have less impact on the decision-capacity than other severe psychiatric or neurological disorders, such as schizophrenia or dementia (Cohen et al., 2004; Palmer et al., 2005; Vollmann et al., 2003). Educational interventions could improve decisional capacity; geriatric patients with depression could helped to attain adequate decisional capacity to consent to electroconvulsive therapy (ECT) (Lapid, Rummans, Pankratz, \& Appelbaum, 2004). Similar results were also reported in patients with schizophrenia (Naughton et al., 2012; Wang et al., 2016). Willingness to participate in studies was also associated with higher MacCAT-CR Seores on the Understanding and Expression of a Choice 
subscales (Candilis, Geppert, Fletcher, Lidz, \& Appelbaum, 2006).

Emotional withdrawal in depression affects the willingness to participate in studies on competence, which, in turn, could worsen decision-making capadity (Redding, 1997).

Finally, the limitation of this review is the heterogeneous collection of studies with different purpose, subject cohorts and versions of the MacCAT. However, all versions assess decision-making competence in similar domains. Further, it should be noted that several studies included in this review had small samples although none of the case studies were included.

In conclusion, the mechanisms mediating the association between depression and decision-making capacity are likely to be complex and multi-factorial, Future research should ascertain the independent association between depression and decision-making capacity. In addition, the reliability and validity of the MacCATs used in different populations and contexts should be further tested to ascertain the usefulness of these instruments

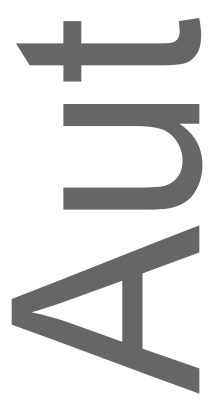




\section{REFERENCES}

Appelbaum, P. S., \& Grisso, T. (1995). The MacArthur Treatment

Competence Study. I: Mental illness and competence to consent to -

treatment. Law and human behavior, 19(2), 105.

Appelbaum,P. S., \& Grisso, T. (2001). MacArthur competence assessment tool for clinical research (MacCAT-CR): Professional Resource Press/Professional Resource Exchange.

Appelbaum, P. S., Grisso, T., Frank, E., O'Donnell, S., \& Kupfer, D. J. (1999). Competence of depressed patients for consent to research. American Journal of Psychiatry, 156(9), 1380-1384. doi: 10-1176/ajp.156.9.1380

Appelbaum, P. S., \& Redlich, A. (2006). Impact of decisional capacity on the use of leverage to encourage treatment adherence. Community Mental Health Journal, 42(2), 121-130. doi:10.1007/s10597-005-9015-6

Appelbaum, P. S., \& Roth, L.H. (1982). Competency to consent to research: A psychiatric overview. Archives of General Psychiatry, 39(8), 951. 
Cairns, R., Maddock, C., Buchanan, A., David, A. S., Hayward, P., Richardson, G., . . . Hotopf, M. (2005). Prevalence and predictors of mental incapacity in psychiatric in-patients. British Journal of Psychiatry, 187, 379-385. doi:10.1192/bjp.187.4.379

Candilis, P. J., Geppert, C. M., Fletcher, K. E., Lidz, C. W., \& Appelbaum, P. S. (2006). Willingness of subjects with thought disorder to participate in research. Schizophrenia Bulletin, 32(1), 159-165. doi:10.1093/schbul/sbj016

Christopher, P., Fisher, C., Appelbaum, P., Holtzheimer, P., Mayberg, H., Lisanby, S., \& Dunn, L. (2011). Deep brain stimulation research for treatment-resistant depression: Empirical investigation of ethical concerns. Neuropsychopharmacology, 36, S121-S122.

Cohen, B. J., McGarvey, E. L., Pinkerton, R. C., \& Kryzhanivska, L. (2004). Willingness and competence of depressed and schizophrenic inpatients to consent to research. Journal of the American Academy of Psychiatry and the Law Online, 32(2), 134-143. 
Dunn, L. B., Nowrangi, M. A., Be, M., Palmer, B. W., Jeste, D. V., \& Saks, E. R. (2006). Assessing decisional capacity for clinical research or treatment: a review of instruments. American Journal of Psychiatry.

Fisher, C. E., Dunn, L. B., Christopher, P. P., Holtzheimer, P. E., Leykin, Y., Mayberg, H. S., . . A Appelbaum, P. S. (2012). The ethics of research on deep brain stimulation for depression: decisional capacity and therapeutic misconception. Annals of the New York Academy of Saiences, 1265(1), 69-79.

Grisso, Appelbaum, P. S. (1995). The MacArthur Treatment Competence Study. III: Abilities of patients to consent to psychiatric and medical treatments. Law and human behavior, 19(2), 149.

Grisso, T., \& Appelbaum, P. S. (1998). Assessing competence to consent to treatment: A guide for physicians and other health professionals: New York, NY, US: Oxford University Press; US.

Grisso, T., Appelbaum, P. S., \& Hill-Fotouhi, C. (1997). The MacCAT-T: a clinical tool to assess patients' capacities to make treatment decisions. Psychiatric Services, 48(11), 1415-1419. doi:10.1176/ps.48.11.1415 
Grisso, T., Appelbaum, P. S., Mulvey, E. P., \& Fletcher, K. (1995). The MacArthur Treatment Competence Study. II: Measures of abilities related to competence to consent to treatment. Law and human behavior, 19(2), 127.

(

Hindmarch, T., Hotopf, M., \& Owen, G. S. (2013). Depression and decision-making capacity for treatment or research: a systematic review. BMC medical ethics, 14(1), 1.

Lamont, S., Jeon, Y. H., \& Chiarella, M. (2013). Assessing patient capacity to consent to treatment: An integrative review of instruments and tools. Journal of clinical nursing, 22(17-18), 2387-2403.

Lapid, M. I., Rummans, T. A., Pankratz, V. S., \& Appelbaum, P. S. (2004). Decisional capacity of depressed elderly to consent to electroconvulsive therapy. Journal of Geriatric Psychiatry and Neurology, 17(1), 42-46. doi:10.1177/0891988703261996

Lapid, M. I., Rummans, T. A., Poole, K. L., Pankratz, V. S., Maurer, M. S., Rasmussen, K. G., . . A Appelbaum, P. S. (2003). Decisional capacity of severely depressed patients requiring electroconvulsive therapy. The journal of ECT, 19(2), 67-72. 
Maxmin, K., Cooper, C., Potter, L., \& Livingston, G. (2009). Mental capacity to consent to treatment and admission decisions in older adult psychiatric inpatients. International Journal of Geriatric Psychiatry, 24(12), 1367-1375. doi:10.1002/gps.2272

Meynen, G. (2011). Depression, possibilities, and competence: a phenomenological perspective. Theoretical medicine and bioethics, $32(3), 181-193$

Naughton, M., Nulty, A., Abidin, Z., Davoren, M., O'Dwyer, S., \& Kennedy, H.G. (2012). Effects of group metacognitive training (MCT) on mental capacity and functioning in patients with psychosis in a secure forensic psychiatric hospital: a prospective-cohort waiting list controlled study. BMC Res Notes, 5, 302. doi: $10.1186 / 1756-0500-5-302$

Owen, G.S., David, A. S., Richardson, G., Szmukler, G., Hayward, P., \& Hotopf, M. (2009). Mental capacity, diagnosis and insight in psychiatric in-patients: a cross-sectional study. Psychological medicine, 39(08), 1389-1398. 
Owen, G. S., Richardson, G., David, A. S., Szmukler, G., Hayward, P., \& Hotopf, M. (2008). Mental capacity to make decisions on treatment in people admitted to psychiatric hospitals: cross sectional study. $B M J$, 337, a448. doi:10.1136/bmj.39580.546597.BE

Palmer, B. W. Dunn, L. B., Appelbaum, P. S., Mudaliar, S., Thal, L., Henry, R. Jeste, D. V. (2005). Assessment of capacity to consent to research among older persons with schizophrenia, Alzheimer disease, or diabetes mellitus: comparison of a 3-item questionnaire with a comprehensive standardized capacity instrument. Archives of GeneralPsychiatry, 62(7), 726-733. doi:10.1001/archpsyc.62.7.726

Poythress, N. G., Bonnie, R. J., Monahan, J., Otto, R., \& Hoge, S. K. (2002). Development of the MacArthur Competence Assessment Tool-Criminal Adjudication (The MacCAT-CA) Adjudicative Competence (pp. 111-144): Springer.

Raymont, V., Bingley, W., Buchanan, A., David, A. S., Hayward, P., Wessely, S., \& Hotopf, M. (2004). Prevalence of mental incapacity in rictice medical inpatients and associated risk factors: cross-sectional study. The Lancet, 364(9443), 1421-1427. 
Redding, R. E. (1997). Depression in jailed women defendants and its relationship to their adjudicative competence. Journal of the American Academy of Psychiatry and the Law, 25(1), 105-119.

E. D. (2005). The capacity to consent to treatment and research:

a review of standardized assessment tools. Clinical psychology review, 25(7), 954-974.

Vellinga, A., Smit, J. H., van Leeuwen, E., van Tilburg, W., \& Jonker, C. (2004). Instruments to assess decision-making capacity: an overview. International Psychogeriatrics, 16(04), 397-419.

Vollmann, 2., Bauer, A., Danker-Hopfe, H., \& Helmchen, H. (2003). Competence of mentally ill patients: a comparative empirical study. Psychological Medicine, 33(8), 1463-1471.

Wang, X., Yu, X., Appelbaum, P. S., Tang, H., Yao, G., Si, T., . . . Li, L. (2016). Longitudinal informed consent competency in stable community patients with schizophrenia: A one-week training and one-year follow-up study. Schizophrenia Research, 170(1), 162-167. doi: 10.1016/j.schres.2015.11.019 
Figure 1. PRISMA flow diagram Table 1. Studies Measuring Decisional Capacity by MacCAT. Comparisons between Participants with Depression, Non-psychiatric Controls or Other Psychiatric Disorders Participants

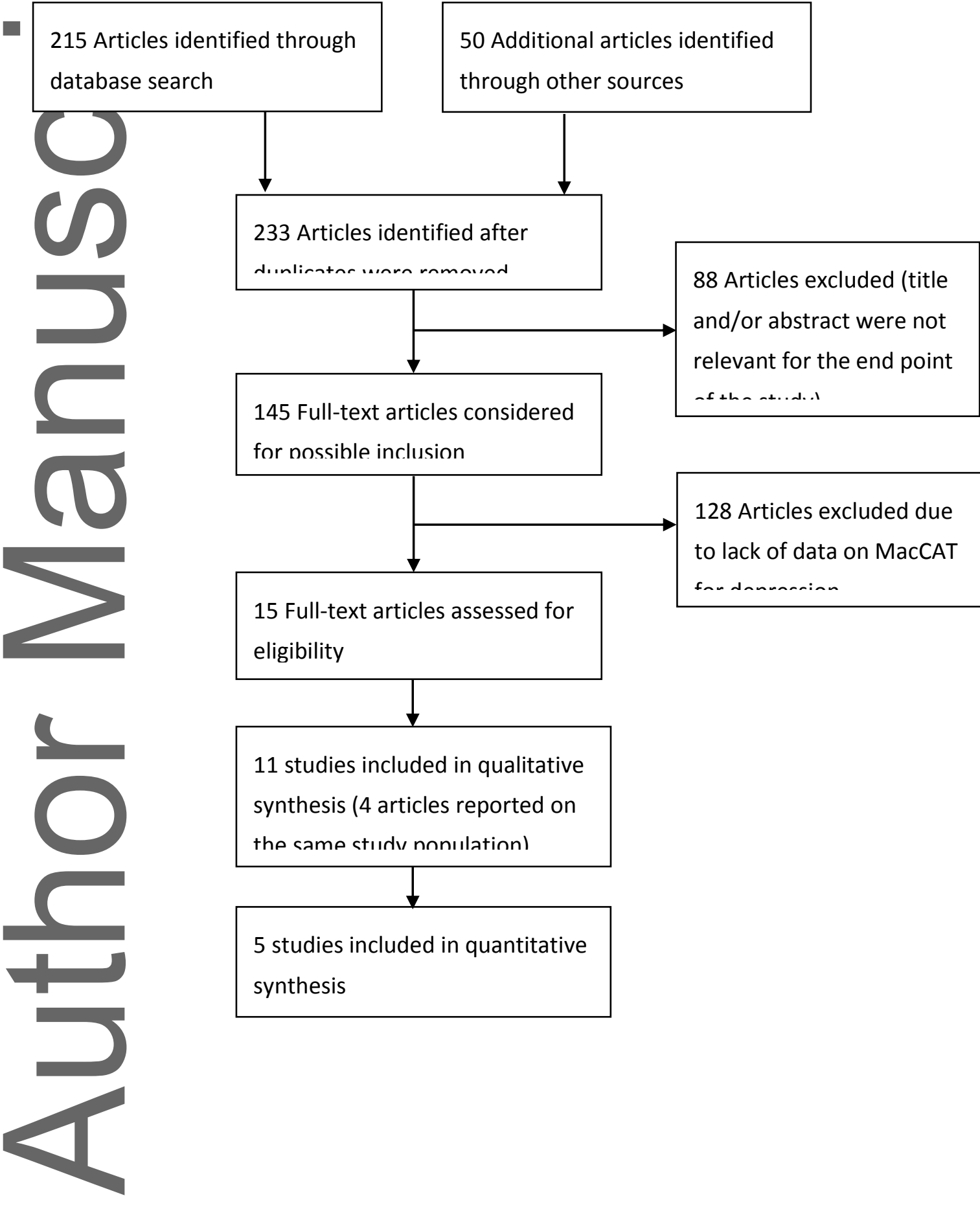




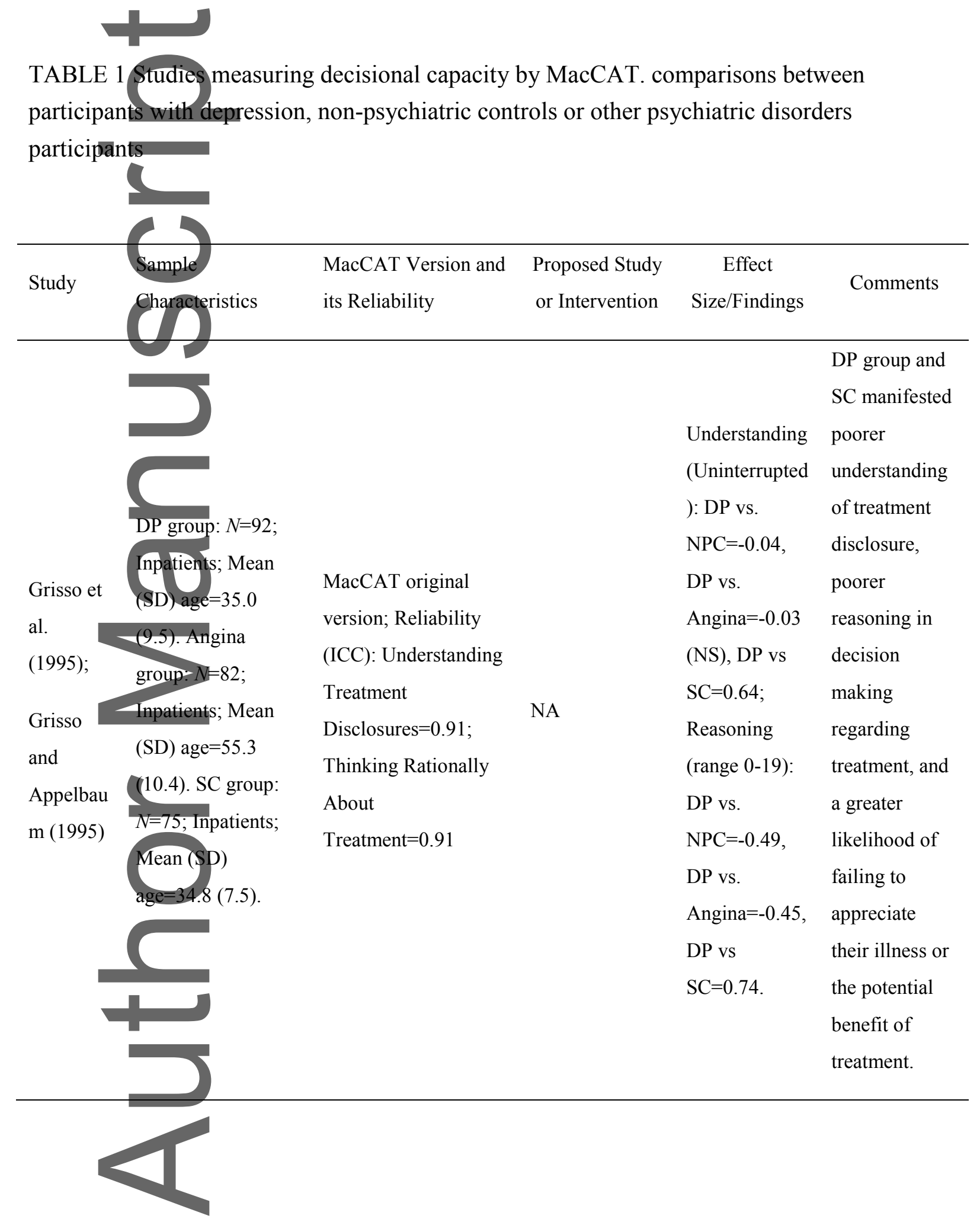

This article is protected by copyright. All rights reserved. 


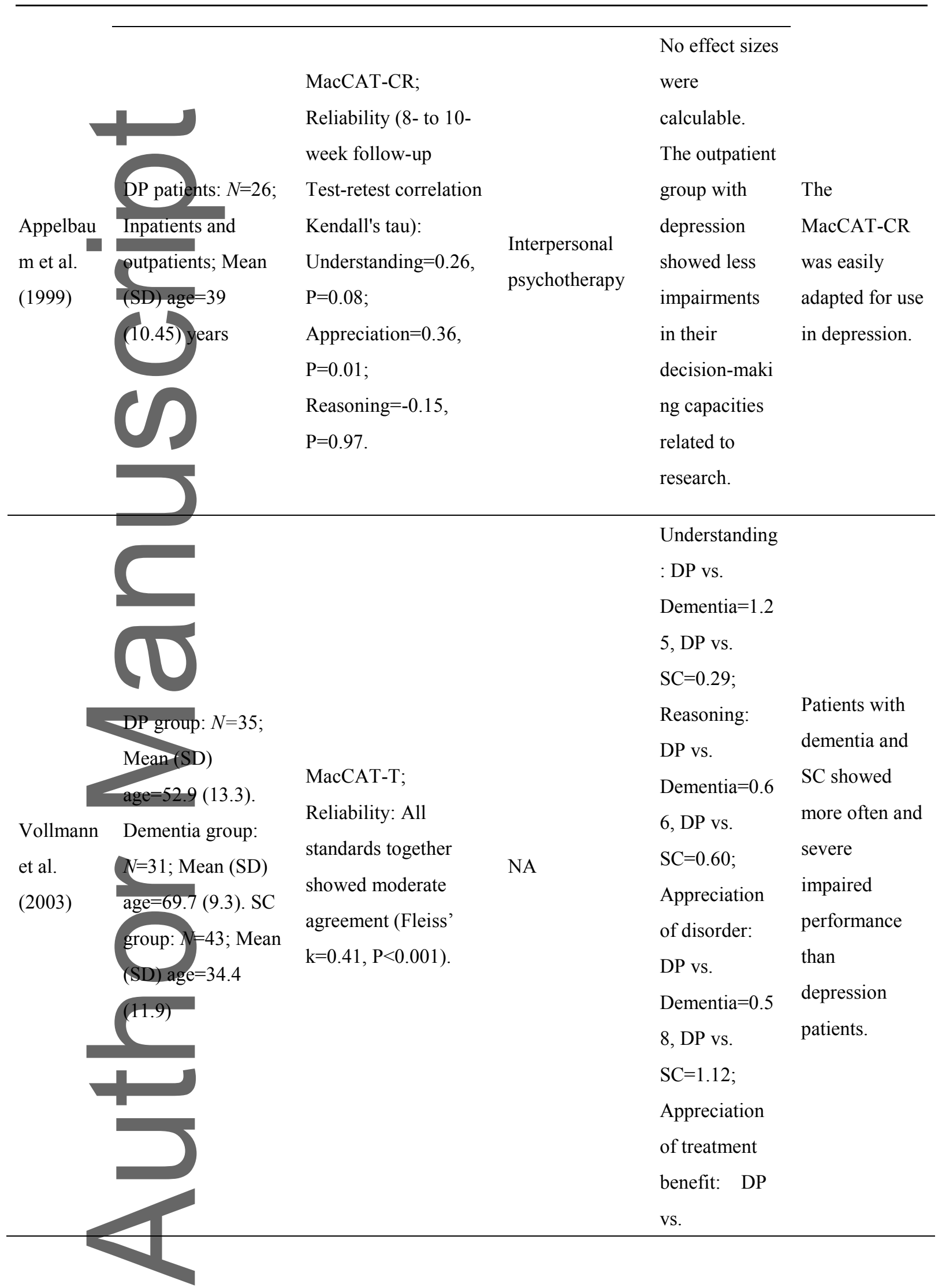

This article is protected by copyright. All rights reserved. 


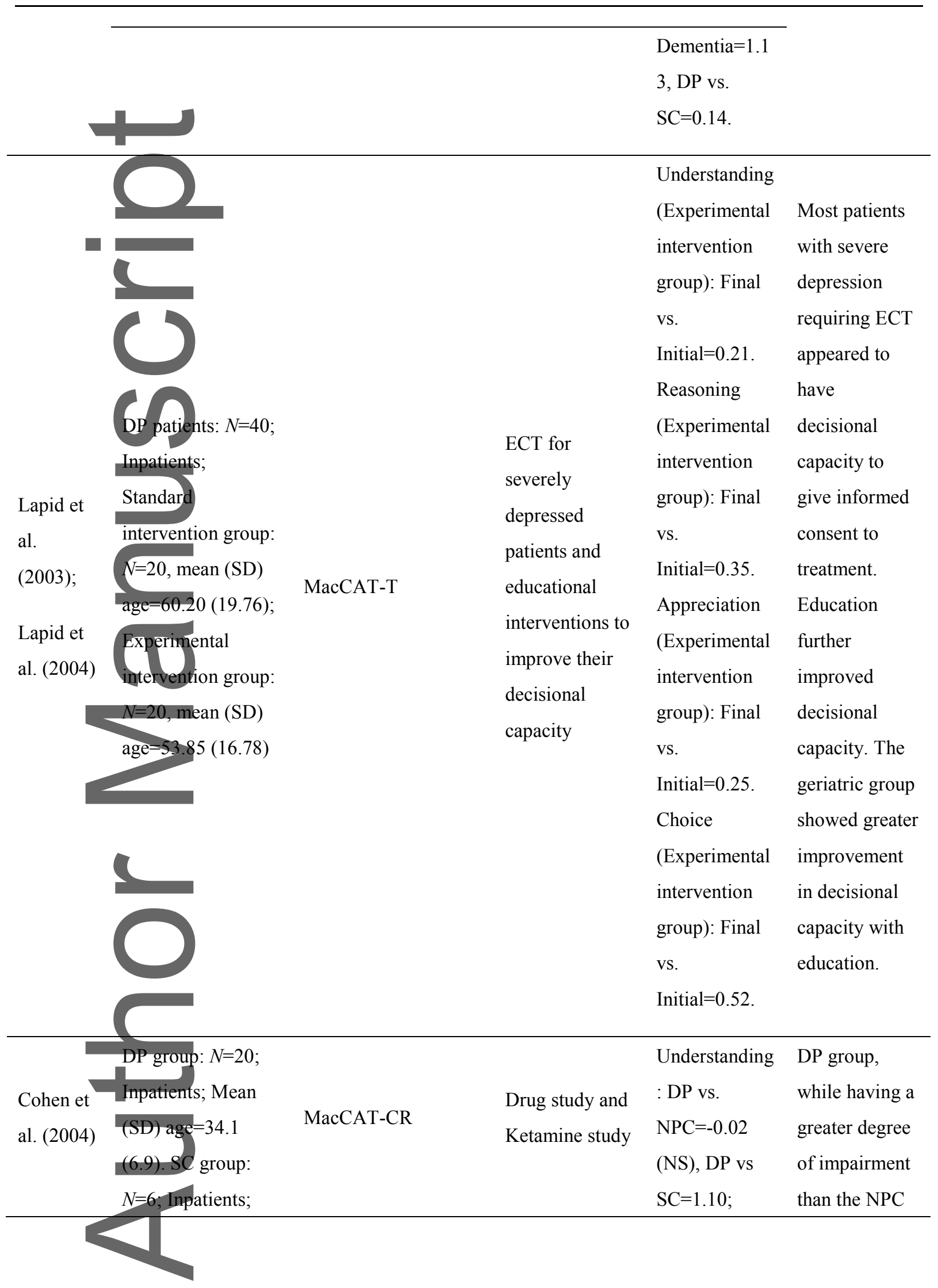

This article is protected by copyright. All rights reserved. 


\begin{tabular}{|c|c|c|c|c|c|}
\hline 口 & $\begin{array}{l}\text { Mean }(\mathrm{SD}) \\
\text { age=40.0 (7.8). } \\
\text { NPC group: } N=20 \text {; } \\
\text { Community } \\
\text { subjects; Mean } \\
\text { (SD) age=41.1 } \\
(10.3) \text {. }\end{array}$ & & & $\begin{array}{l}\text { Appreciation: } \\
\mathrm{DP} \text { vs. } \\
\mathrm{NPC}=-0.69 \\
\mathrm{DP} \text { vs. } \\
\mathrm{SC}=1.28 \\
\text { Reasoning: } \\
\mathrm{DP} \text { vs. } \\
\mathrm{NPC}=-0.85 \\
\mathrm{DP} \text { vs. } \\
\mathrm{SC}=0.74\end{array}$ & $\begin{array}{l}\text { group, still } \\
\text { demonstrated } \\
\text { relatively high } \\
\text { decision-maki } \\
\text { ng capacity } \\
\text { and was able } \\
\text { to distinguish } \\
\text { levels of risk } \\
\text { between } \\
\text { studies. Their } \\
\text { pattern of } \\
\text { preferences } \\
\text { did not differ } \\
\text { from that of } \\
\text { the control } \\
\text { subjects. } \\
\text { However, they } \\
\text { were more } \\
\text { likely to refuse } \\
\text { to participate } \\
\text { in the research. }\end{array}$ \\
\hline $\begin{array}{l}\text { Cairns et } \\
\text { al. (2005) }\end{array}$ & $\begin{array}{l}\text { PP Group: } N=25 \text {; } \\
\text { npatients. Other } \\
\text { sychotic disorder } \\
\text { jroup: } N=87 \text {; } \\
\text { inpatients. }\end{array}$ & $\begin{array}{l}\text { MacCAT-T; } \\
\text { Reliability } \\
(\text { kappa })=0.82\end{array}$ & NA & $\begin{array}{l}\text { Four }(16.0 \%) \\
\text { DP patients, } \\
\text { lack } \\
\text { treatment-relat } \\
\text { ed decisional } \\
\text { capacity. Lack } \\
\text { of } \\
\text { treatment-relat } \\
\text { ed decisional } \\
\text { capacity is a } \\
\text { common but } \\
\text { by no means }\end{array}$ & $\begin{array}{l}\text { England and } \\
\text { Wales Draft } \\
\text { Mental } \\
\text { Incapacity } \\
\text { Bill's } \\
\text { definition of } \\
\text { mental } \\
\text { incapacity was } \\
\text { used to reach a } \\
\text { binary (yes/no) } \\
\text { decision. }\end{array}$ \\
\hline
\end{tabular}

This article is protected by copyright. All rights reserved. 


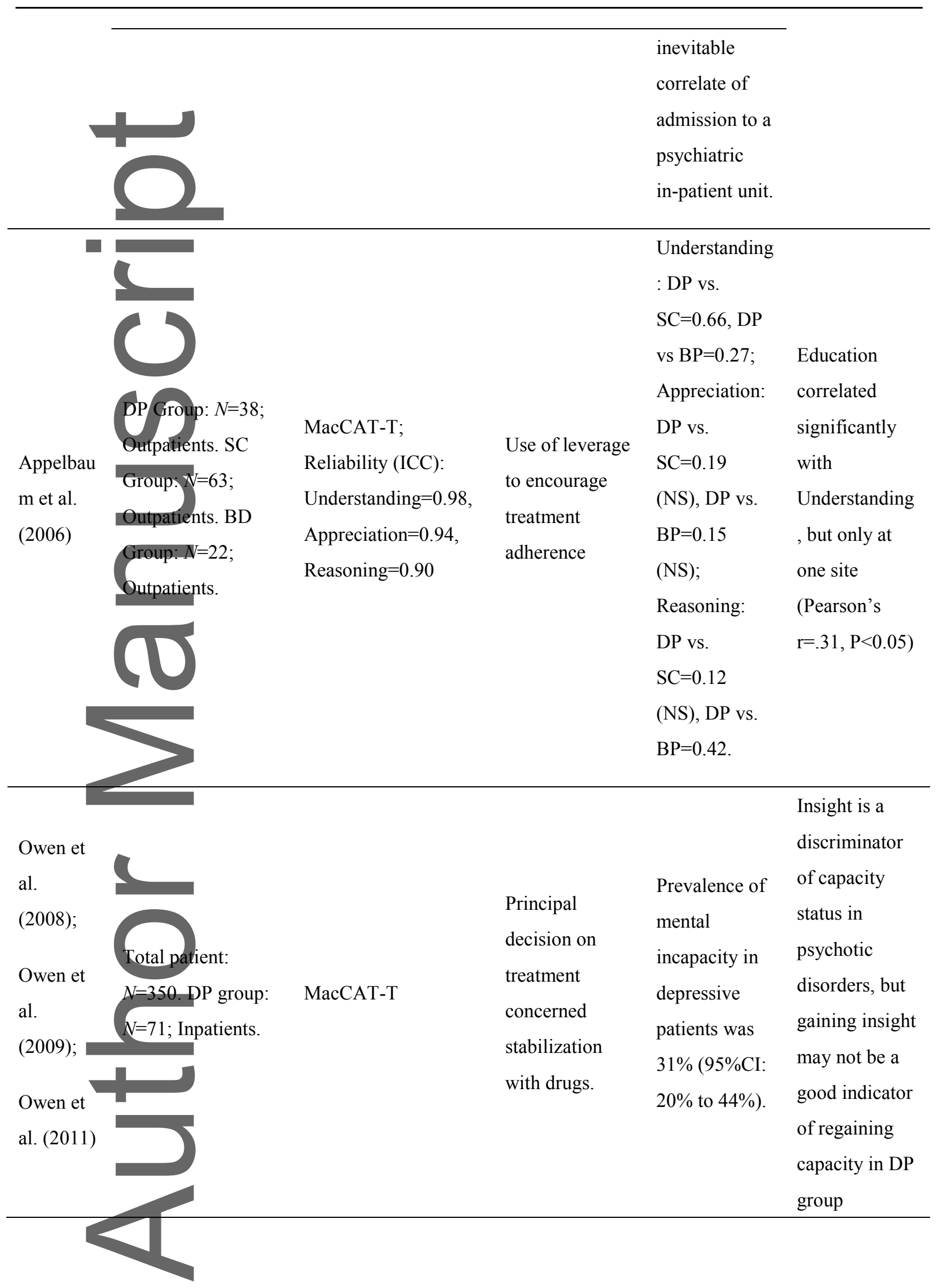

This article is protected by copyright. All rights reserved. 


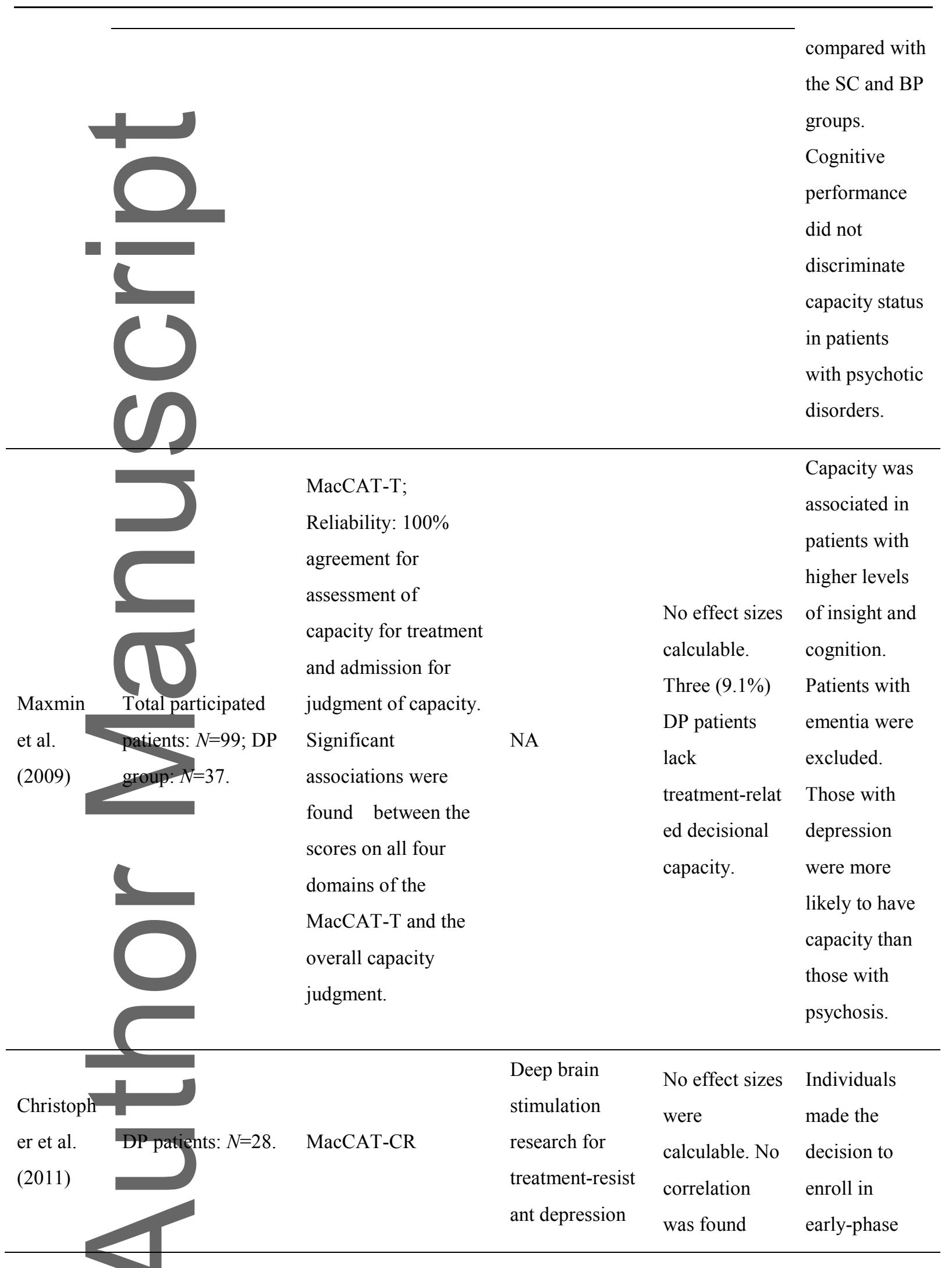

This article is protected by copyright. All rights reserved. 


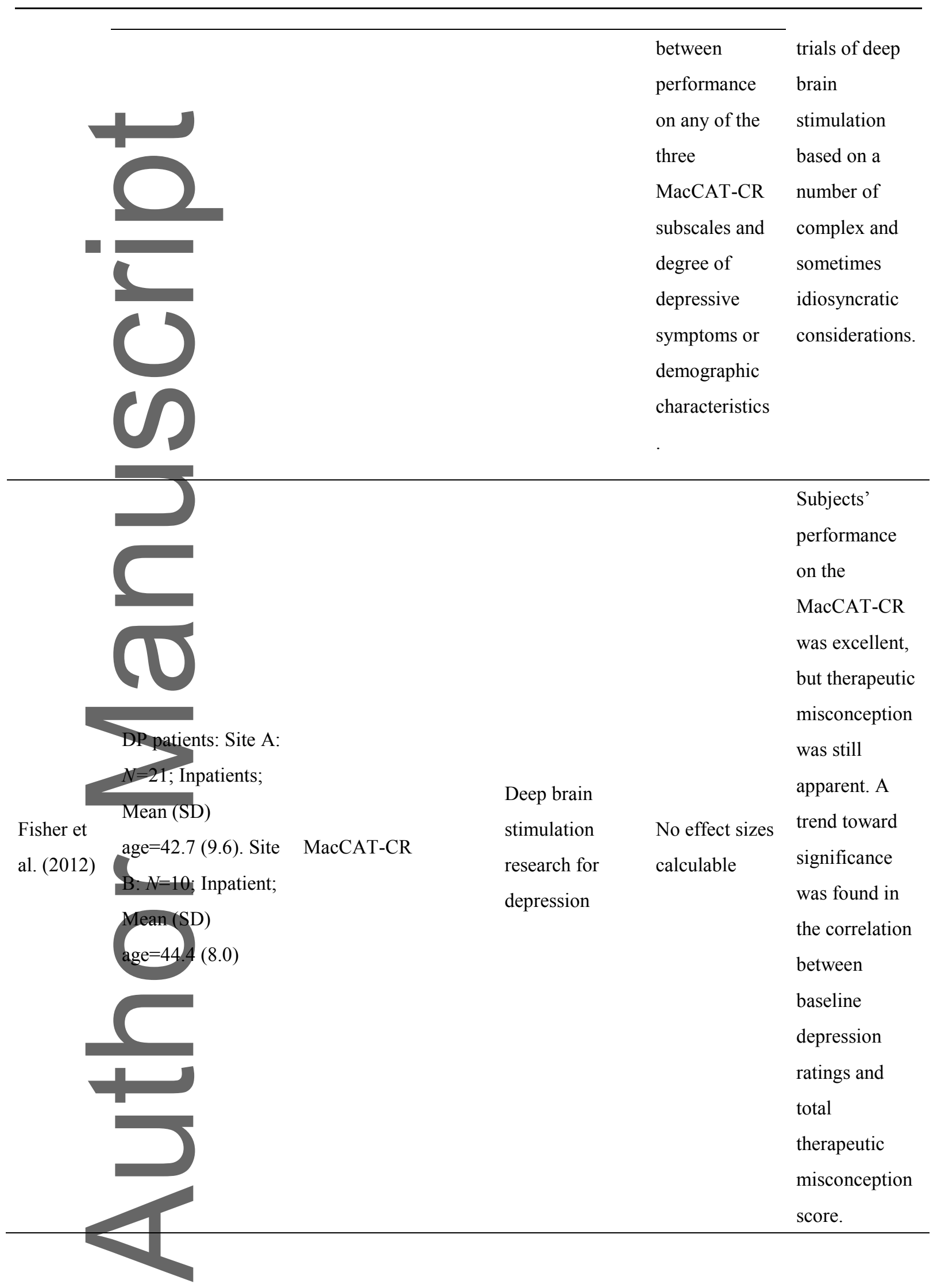

This article is protected by copyright. All rights reserved. 


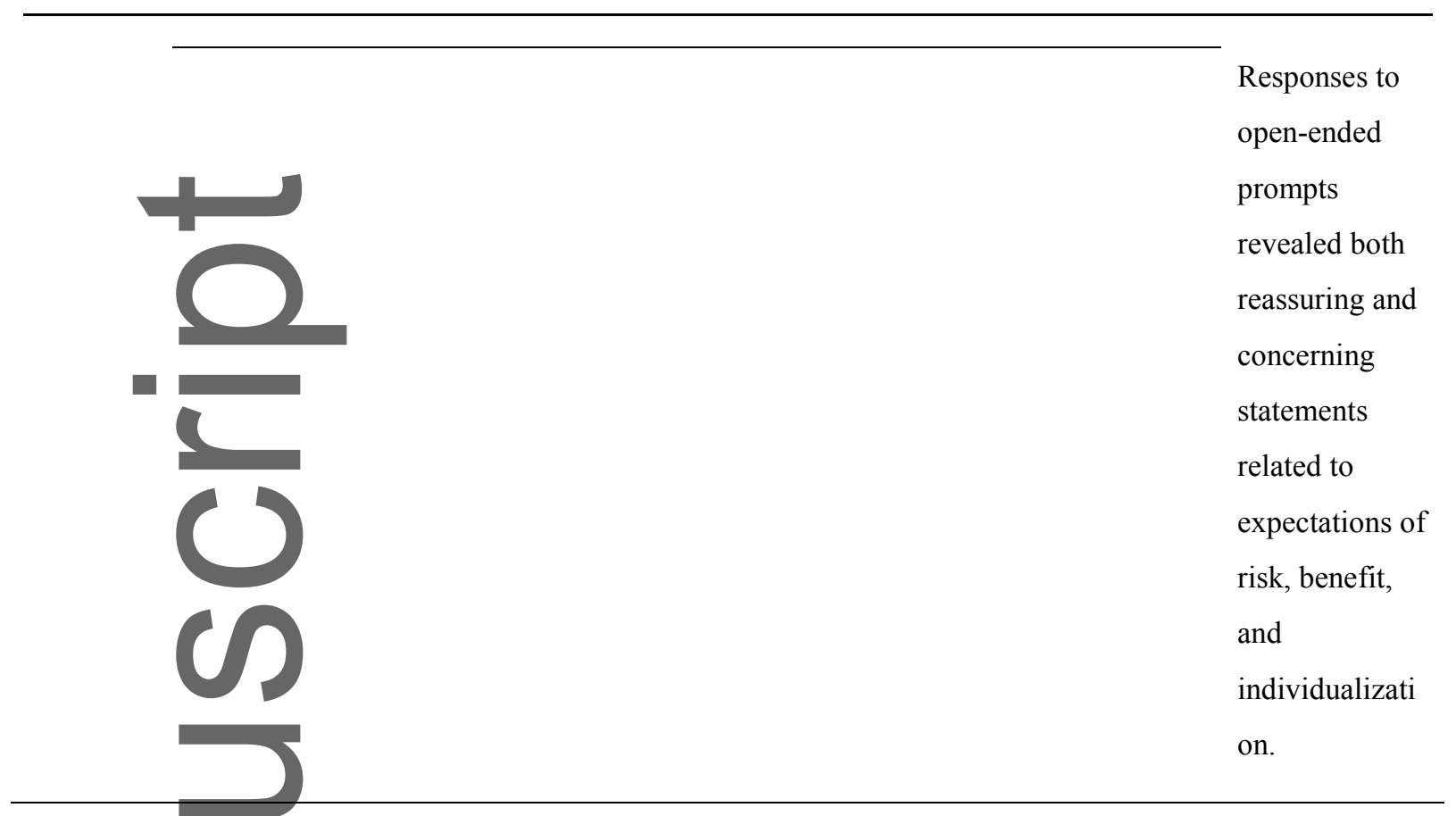

Note: $\mathrm{BD}=$ Bipolar Disorder; $\mathrm{CI}=$ Confidence Interval; $\mathrm{DP}=$ Depression; Electroconvulsive therapy=ECT; ICC=Interclass Correlation Coefficient; IQR=Interquartile range; MacCAT-CR=MacAthur Competence Assessment Tool for Clinical Research; MacCAT-T=MacArthur Competence Assessment Tool for Treatment; $\mathrm{NA}=$ Not Available; NPC=Non-psychiatric Comparison participants; NS=Non-significant; SD=Standard deviation.

This article is protected by copyright. All rights reserved. 


\section{University Library}

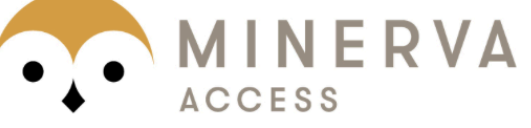

A gateway to Melbourne's research publications

Minerva Access is the Institutional Repository of The University of Melbourne

Author/s:

Wang, Y-Y;Wang, S-B;Ungvari, GS;Yu, X;Ng, CH;Xiang, Y-T

Title:

The assessment of decision-making competence in patients with depression using the MacArthur competence assessment tools: A systematic review

Date:

2018-04-01

Citation:

Wang, Y. -Y., Wang, S. -B., Ungvari, G. S., Yu, X., Ng, C. H. \& Xiang, Y. -T. (2018). The assessment of decision-making competence in patients with depression using the MacArthur competence assessment tools: A systematic review. PERSPECTIVES IN PSYCHIATRIC CARE, 54 (2), pp.206-211. https://doi.org/10.1111/ppc.12224.

Persistent Link:

http://hdl.handle.net/11343/292929 